\title{
Desequilibrios económicos territoriales en El Salvador
}

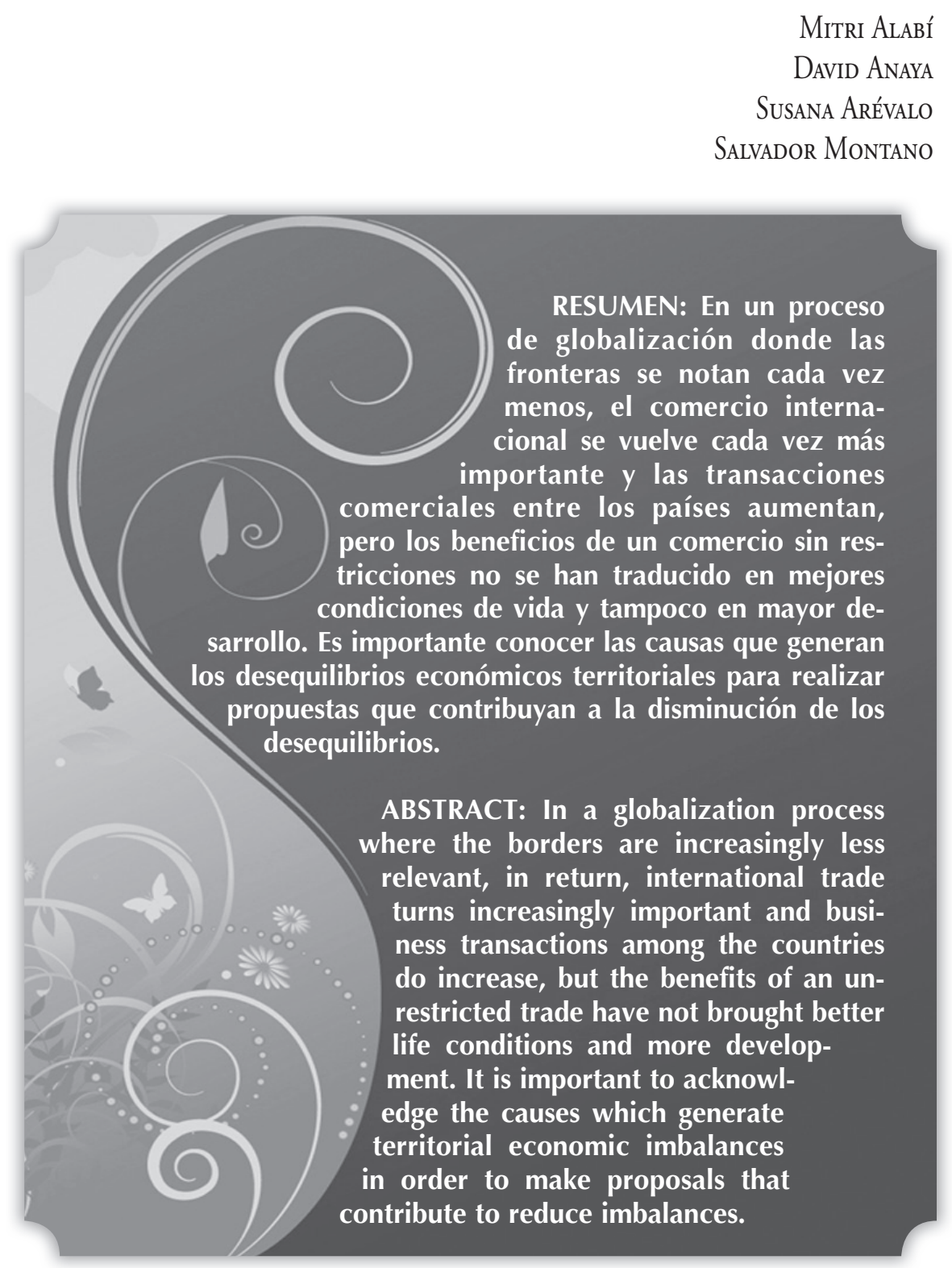


$\mathrm{E}$ n un proceso de globalización donde las fronteras se notan cada vez menos, el comercio internacional se vuelve cada vez más importante y las transacciones comerciales entre los países aumentan, pero los beneficios de un comercio sin restricciones no se han traducido en mejores condiciones de vida y tampoco en mayor desarrollo.

Diferentes esferas de la sociedad han mostrado interés en estudiar las causas de estos desequilibrios. pues son fundamentales para brindar soluciones integrales a estas disparidades entre los territorios y las poblaciones.

Por un lado, el Estado salvadoreño ha mostrado interés en abordar estas disparidades lanzando el Plan Nacional de Ordenamiento Territorial:
"La política territorial contiene los lineamientos para impulsar el ordenamiento y el desarrollo territorial sostenible, la competitividad del país y el desarrollo humano, con el objetivo primordial de asegurar el pleno aprovechamiento del territorio y sus recursos y mejorar así la calidad de vida de la población salvadoreña." (Saca, 2008)

Por otra parte, se encuentran instituciones dedicadas al estudio de la economía en el país. Por ejemplo, la Fundación Nacional para el Desarrollo (FUNDE) y la Universidad Centroamericana José Simeón Canas (UCA), entre otras.

Es importante conocer las causas que generan los desequilibrios económicos territoriales para realizar propuestas o al menos generar insumos que contribuyan a la disminución o regulación de los desequilibrios.

\section{Principales desequilibrios económicos territoriales en El Salvador}

En esta sección se describen los principales desequilibrios económicos territoriales existentes en la economía salvadoreña, tomando en cuenta desequilibrios económicos que se ven presentes en los sectores de la economía salvadoreña, como la industria, comercio, construcción, servicios y agricultura. Se enunciarán algunos rasgos caracte- rísticos de la economía salvadoreña, como la densidad poblacional, niveles de empleo, pobreza, educación, acceso a servicios públicos, remesas, etc. los cuales contribuirán a presentar mayores elementos para evidenciar que en diferentes ámbitos productivos los desequilibrios económicos territoriales se encuentran en El Salvador. 
Se recurrirá a la información recopilada en los VII Censos Económicos de 2005, que son fuente de información estadística confiable para la interpretación de problemas económicos que contribuyan al desarrollo de la economía de El Salvador. Además se utilizará la Matriz Insumo Producto (MIP) con el objetivo de tener una idea general del nivel de articulación con los diferentes sectores del aparato productivo y su incidencia o relación con los desequilibrios económicos territoriales con respecto al territorio geográfico y a los sectores productivos de la economía salvadoreña.

\subsection{Principales resultados}

\subsubsection{Ingreso per cápita}

\section{Cuadro 2.1 \\ Ingreso per cápita mensual 2005 (en dólares)}

\begin{tabular}{|c|c|}
\hline Departamento & Ingreso per cápita \\
\hline Ahuachapán & 80.98 \\
\hline Santa Ana & 80.46 \\
\hline Sonsonate & 99.21 \\
\hline Chalatenango & 85.44 \\
\hline La Libertad & 110.16 \\
\hline San Salvador & 144.4 \\
\hline Cuscatlán & 64.78 \\
\hline La Paz & 80.96 \\
\hline Cabañas & 64.78 \\
\hline San Vicente & 80.22 \\
\hline Usulután & 77.16 \\
\hline San Miguel & 93.87 \\
\hline Morazán & 79.93 \\
\hline La Unión & 83.19 \\
\hline
\end{tabular}

FUENTE: Elaboración propia en base a EHPM 2005 


\begin{tabular}{|c|c|}
\hline \multicolumn{2}{|c|}{$\begin{array}{c}\text { Cuadro } 2.2 \\
\text { PIB per cápita Anual por departamento }\end{array}$} \\
\hline Departamento & PIB per cápita anual (US\$) \\
\hline San Salvador & 7,073 \\
\hline La Libertad & 5,463 \\
\hline Sonsonate & 4,490 \\
\hline San Miguel & 4,482 \\
\hline Santa Ana & 4,112 \\
\hline Chalatenango & 4,045 \\
\hline La Unión & 3,802 \\
\hline Usulután & 3,709 \\
\hline La Paz & 3,683 \\
\hline Cuscatlán & 3,557 \\
\hline Ahuachapán & 3,437 \\
\hline San Vicente & 3,297 \\
\hline Cabañas & 3,222 \\
\hline Morazán & 3,040 \\
\hline
\end{tabular}

FUENTE: Elaboración propia en base a "Informe sobre Desarrollo Humano",

Compendio Estadístico, 2005

Haciendo un promedio del PIB per cápita distribuido para las tres zonas político administrativas del país: occidental, central y oriental (Cuadro 2.3).

\section{Cuadro 2.3 \\ PIB per cápita por zona}

\begin{tabular}{cc}
\hline Zona & PIB per capita anual (US\$) \\
\hline Occidental & $4,013.00$ \\
Central & $4,334.28$ \\
\hline Oriental & $3,758.25$ \\
\hline
\end{tabular}

FUENTE: Elaboración propia en base al "Informe sobre Desarrollo Humano", Compendio Estadístico, 2005. 
2.1.3 Pobreza

Uno de los Objetivos de Desarrollo del Milenio (ODM) pro- puesto por la Organización de las Naciones Unidas, de la cual forma parte El Salvador, es reducir la pobreza. Esta es definida como:

"[La] carencia de los bienes y servicios necesarios para satisfacer las necesidades básicas. Concepto de índole relativa: se es pobre - o rico- con respecto a la situación de otras personas o países, pues la misma idea de necesidades "básicas" es imprecisa y porque los individuos nunca pueden satisfacer por completo sus necesidades" (PNUD, 2008).

En el Cuadro 2.4 se observan los datos del porcentaje de hogares que se encuentran en situación de

pobreza en cuanto al nivel de ingreso, tanto relativa como extrema, según departamento.

Cuadro 2.4

Hogares en pobreza relativa y extrema según departamento (2005) \%

\begin{tabular}{|c|c|c|}
\hline Departamento & $\begin{array}{c}\text { Hogares en Pobreza } \\
\text { Relativa }\end{array}$ & $\begin{array}{c}\text { Hogares en Pobreza } \\
\text { Extrema }\end{array}$ \\
\hline Ahuachapán & 45.0 & 29.3 \\
\hline Cabañas & 53.0 & 30.7 \\
\hline Chalatenango & 41.9 & 28.7 \\
\hline Cuscatlán & 46.9 & 14.9 \\
\hline La Libertad & 28.8 & 10.6 \\
\hline La Paz & 40.9 & 19.9 \\
\hline La Unión & 35.0 & 17.4 \\
\hline Morazán & 55.3 & 27.2 \\
\hline San Miguel & 38.7 & 20.1 \\
\hline San Salvador & 24.0 & 8.3 \\
\hline San Vicente & 55.0 & 27.8 \\
\hline Santa Ana & 38.7 & 18.1 \\
\hline Sonsonate & 39.1 & 18.3 \\
\hline Usulután & 44.3 & 21.7 \\
\hline
\end{tabular}

Fuente: Informe Sobre Desarrollo Humano, PNUD (2005)

\subsubsection{Inversión pública}

La inversión pública es todo empleo de recursos públicos utilizado para incrementar o mejorar el capital físico y humano existente, con el objetivo de ampliar la capacidad de prestar servicios o producir bienes. La inversión pública en El
Salvador se ha caracterizado por ser muy baja e insuficiente, en los últimos diez años ha rondado el $3 \%$ del PIB.

El problema de tener un nivel bajo de inversión es que se resta oportunidades de desarrollo. "Es difícil que El Salvador mantenga el 
4\% de crecimiento económico si no invierte en infraestructura y capital humano" (Acevedo, 2007).

La situación empeora al darnos cuenta de que el departamento que mayor inversión pública recibe es San Salvador con un 19.38\% (Grá- fico 2.1) y departamentos como Morazán, Ahuachapán, Cabañas, que son los más pobres, son los que reciben menos. Ciertamente, si no hay una equidad en la distribución y administración de los fondos, el desarrollo no llegará a todos los sectores.

\section{Gráfico 2.1 \\ Inversión pública según departamentos}

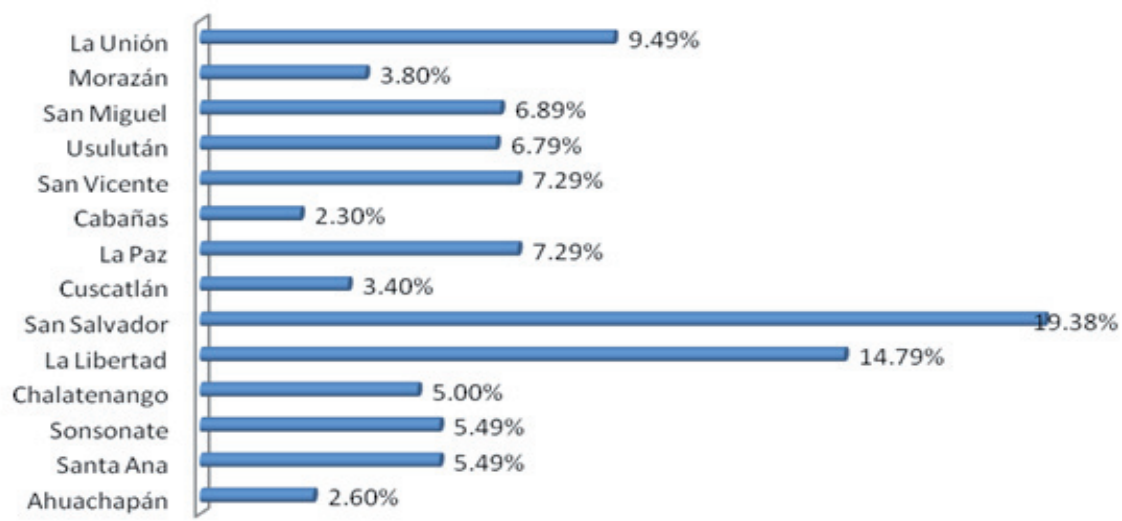

FUENTE: Elaboración propia en base a datos del BCR

\subsection{Desequilibrios económicos territoriales en El Salvador}

Para identificar los desequilibrios económicos territoriales se hará uso de los VII Censos Económicos de 2005, ya que estos proporcionan información confiable sobre las actividades económicas desempeñadas en el territorio nacional, así como también la estructura y distribución de las mismas, permitiendo la implementación y desarrollo de políticas que contribuyan al mejoramiento de los sectores económicos que dinamizan la economía en menor proporción. Posteriormente se utilizará la Matriz Insumo Producto (MIP) para obtener un grado de articulación de la economía y su incidencia o relación con los desequilibrios económicos territoriales. 


\subsubsection{Principales resultados}

\subsubsection{Sector industrial}

Con el incremento de las zonas industriales, se va observando una tendencia a la aglomeración industrial, una concentración que busca obtener ventajas con respecto a la localización de sus actividades productivas y la mano de obra que demanda.

El gráfico 2.2 muestra que la elaboración de alimentos y bebidas, la fabricación de productos textiles, fabricación de prendas de vestir y la fabricación de sustancias químicas, suponen más del $50 \%$ de las ventas, la producción bruta y el personal que ocupa el sector industria.

Fuente: Elaboración propia, basada en el primer capítulo del VII censo económico, 2005.

En el gráfico 2.3 se muestra cómo el mayor porcentaje de la industria se encuentra en los departamentos de San Salvador, La
Libertad, San Miguel y Santa Ana, sumando entre estos cuatro departamentos el 66.78 por ciento de los establecimientos industriales. 


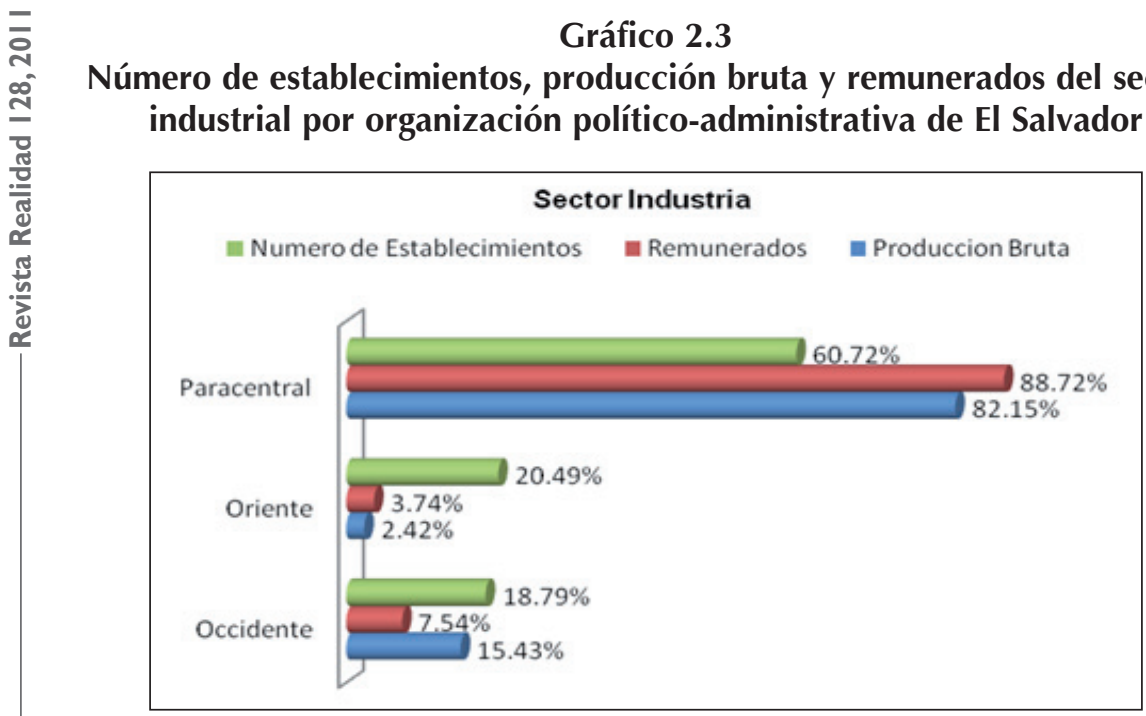

Fuente: Elaboración propia, basada en el VII censo económico, 2005

\subsubsection{Sector comercio}

El sector comercio es uno de los sectores más importantes al posicionarse en el segundo que más contribuye a la formación del Producto Interno Bruto. Este sector ha experimentado un periodo de crecimiento ya que en las últimas décadas se ha tenido una transición de una economía agrícola a una principalmente de manufactura, servicios y comercio.
En el gráfico número 2.4 se puede observar con más detalle el número de establecimientos, producción bruta, remunerados y la formación bruta de capital fijo relacionada a este sector.

El departamento de San Salvador es el que mayor número de establecimientos posee con un $36.38 \%$ seguido de Santa Ana y La Libertad con alrededor del 10\%, los demás departamentos poseen un número considerablemente menor, por ejemplo, en Morazán Ilega a sólo un $2 \%$ del total nacional 
Gráfico 2.4

Número de establecimientos, producción bruta, remunerados y formación bruta de capital fijo del sector comercio por organización político administrativa de El Salvador.

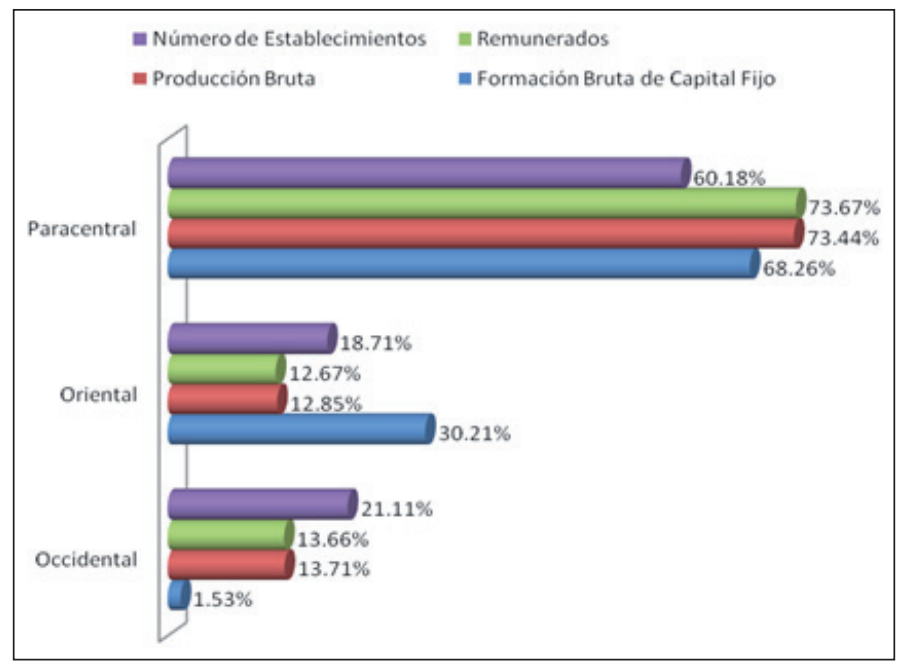

Fuente: Elaboración propia, basada en el VII censo económico, 2005

\subsubsection{Sector construcción.}

Después de la guerra civil, este sector ha tenido en general un desempeño positivo, debido a la necesidad de reconstrucción de la infraestructura dañada durante el conflicto armado y también debido al aumento del crédito al sector privado y a la inversión nacional y extranjera, ya que se contaba con una mayor confianza para invertir.
Según Cabrera, O. (2005), el sector construcción constituye uno de los pilares en cualquier economía puesto que es un sector dinamizante del resto de industrias, es decir, tiene un efecto multiplicador de la actividad económica. El sector construcción es parte de las industrias claves. Estas son importantes ya que,

"Las INDUSTRIAS CLAVES al ser impulsadas afectan a otras muchas y pueden dar lugar a un incremento generalizado de la actividad económica, por ser fuertemente demandantes de insumos intermedios y estar, además, sus ofertas y demandas muy distribuidas entre las ramas" (Cabrera, 2005). 
En el gráfico 2.5 se observa con mayor detalle los indicadores económicos del sector construcción.

A diferencia del sector comercio, el de construcción no cuenta con muchos establecimientos, solamente participa con el 0.3 por ciento equivalentes a 447 del total localizados en el territorio nacional. La mayoría se concentran en el departamento de San Salvador con un 57.7 por ciento. El 30 por ciento del total de establecimientos del sector cuenta con 4 o menos ocupados, es decir que los 313 restantes contratan a 5 o más ocupados (Censos, 2005).

\section{Gráfico 2.5}

Número de establecimientos, producción bruta, remunerados y formación bruta de capital fijo del sector construcción por organización político administrativa de El Salvador.

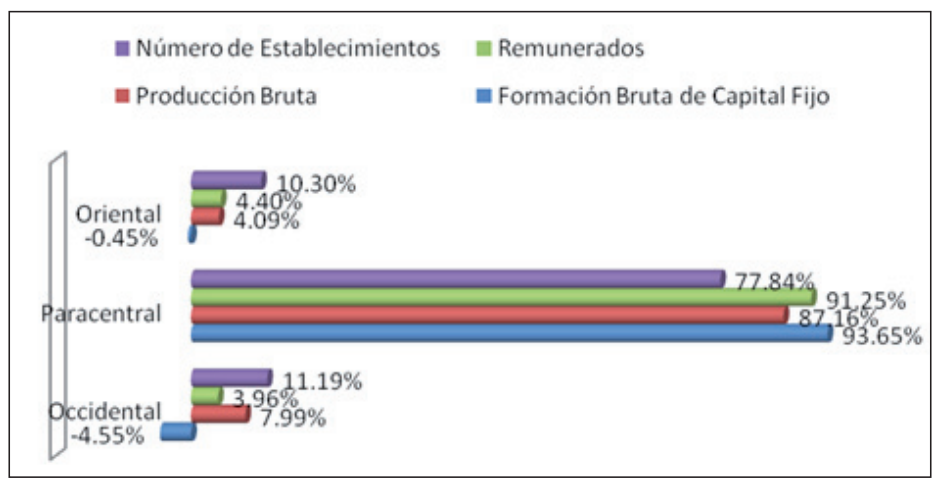

Fuente: Elaboración propia, basada en el VII censo económico, 2005

\subsubsection{Sector servicios}

La economía salvadoreña se caracteriza por estar basada en el sector servicios, el cual está compuesto por: hoteles, restaurantes, construcción, comercios, agua, etc. Durante los últimos 10 años este ha representado el $65 \%$ del PIB.

De acuerdo al Directorio Económico 2005 el mayor número de establecimientos de este sector se encuentran concentrados en la zona paracentral (Gráfico 2.6) específicamente en el departamento de San Salvador con un total de 14,451 , lo cual representa un $44.91 \%$ del total de establecimientos en el país. La Libertad, Santa Ana y San Miguel son los departamentos que siguen con un $11.94 \%$, $9.61 \%$ y $8.24 \%$ respectivamente. Los otros 10 departamentos se reparten el $25.3 \%$ restante, lo que deja en evidencia los grandes desequilibrios económicos territoriales. 
Gráfico 2.6

Número de establecimientos, producción bruta, remunerados, FBKF y ventas del sector servicios por organización político administrativa de El Salvador.

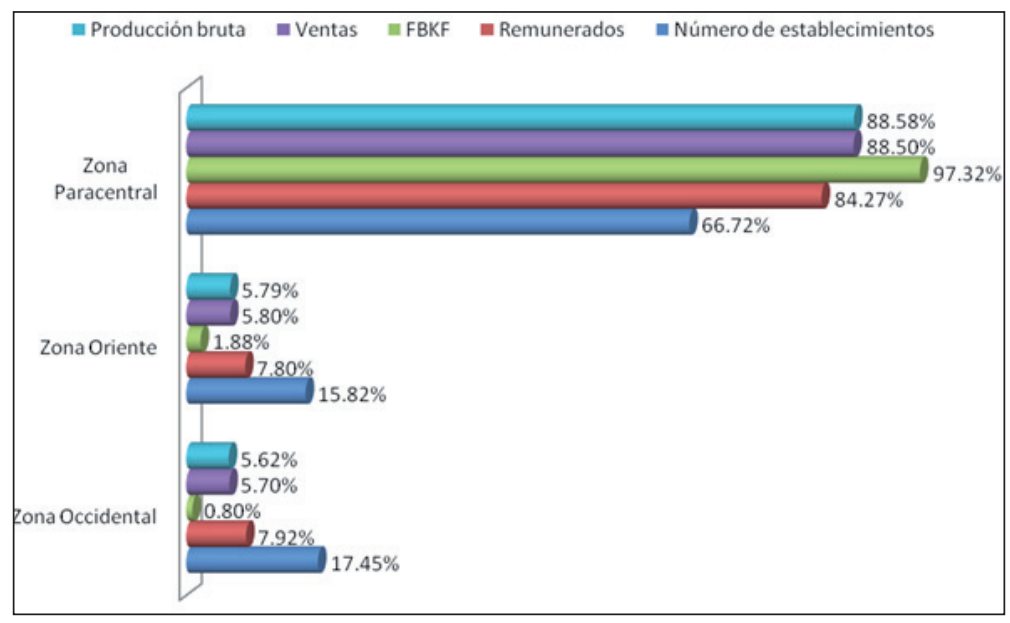

Fuente: Elaboración propia, basada en el VII censo económico, 2005

\subsubsection{Sector Agrícola}

El sector agrícola y principalmente los productos para exportación (café, algodón, arroz, caña de azúcar), fue por muchos años un sector muy importante para la economía salvadoreña debido a su participación en el Producto Interno Bruto (Cuadro 2.5) y porque era una importante fuente de ingresos y empleo para el país, principalmente en el área rural.

Cuadro 2.5

Participación de los principales rubros del sector agrícola en el PIB (\%)

(1962-1965)

\begin{tabular}{lrrrr}
\hline \multicolumn{1}{c}{ Año/producto } & $\mathbf{1 9 6 2}$ & $\mathbf{1 9 6 3}$ & $\mathbf{1 9 6 4}$ & \multicolumn{1}{c}{$\mathbf{1 9 6 5}$} \\
\hline Café & $11.86 \%$ & $11.08 \%$ & $12.50 \%$ & $12.06 \%$ \\
Algodón & $5.04 \%$ & $5.56 \%$ & $4.97 \%$ & $4.74 \%$ \\
Caña de azúcar & $0.39 \%$ & $0.36 \%$ & $0.38 \%$ & $0.24 \%$ \\
Arroz & $0.03 \%$ & $0.05 \%$ & $0.05 \%$ & $0.07 \%$ \\
Total & $\mathbf{1 7 . 3 1 \%}$ & $\mathbf{1 7 . 0 5 \%}$ & $\mathbf{1 7 . 9 0 \%}$ & $\mathbf{1 7 . 1 1} \%$ \\
\hline
\end{tabular}

Fuente: Elaboración propia a partir de datos del BCR 
La caída de este sector a partir de la década de los 70 hasta la actualidad (Cuadro 2.6), se puede atribuir a varios factores, entre los cuales podemos mencionar:

- Las reformas agrarias que se implementaron en la década de los 80 durante la guerra civil en El Salvador.

- Las medidas de corte neoliberal implementadas desde 1990 por los gobiernos de ARENA que terminan favoreciendo al sector financiero y al sector servicios.

\section{Cuadro 2.6}

\section{Participación del sector agrícola en el PIB (\%) (1990-2007)}

\begin{tabular}{|cccc}
\hline Año & $\begin{array}{c}\text { PIB(1990) } \\
\text { Millones de dólares }\end{array}$ & Sector Agrícola (1990) & S.A/PIB \\
\hline 1990 & $4,800.9$ & 534.7 & $11.14 \%$ \\
\hline 1991 & $4,972.5$ & 538.2 & $10.82 \%$ \\
\hline 1992 & $5,347.7$ & 600.7 & $11.23 \%$ \\
\hline 1993 & $5,741.8$ & 587.8 & $10.24 \%$ \\
\hline 1994 & $6,089.3$ & 542.8 & $8.91 \%$ \\
\hline 1995 & $6,478.7$ & 566.2 & $8.74 \%$ \\
\hline 1996 & $6,589.2$ & 576.1 & $8.74 \%$ \\
\hline 1997 & $6,869.0$ & 568.51 & $8.28 \%$ \\
\hline 1998 & $7,126.5$ & 548.8 & $7.70 \%$ \\
\hline 1999 & $7,372.3$ & 608.7 & $8.26 \%$ \\
\hline 2000 & $7,531.0$ & 567.1 & $7.53 \%$ \\
\hline 2001 & $7,659.7$ & 543 & $7.09 \%$ \\
\hline 2002 & $7,839.0$ & 537.6 & $6.86 \%$ \\
\hline 2003 & $8,019.3$ & 534 & $6.66 \%$ \\
\hline 2004 & $8,167.7$ & 544.9 & $6.67 \%$ \\
\hline 2005 & $8,419.7$ & 574.9 & $6.83 \%$ \\
\hline 2006 & $8,772.0$ & 622.3 & $7.09 \%$ \\
\hline 2007 & $9,179.9$ & 683.4 & $7.44 \%$ \\
\hline
\end{tabular}

Fuente: Elaboración propia a partir de datos del BCR

La superficie que se cultiva en El Salvador ronda aproximadamente las 700,000 hectáreas de las cuales el $28 \%$ se utiliza para cultivar café, el 30\% para maíz, 15\% para el frijol, $13 \%$ para el sorgo, $12 \%$ a la caña de azúcar, $1 \%$ al arroz y un $1 \%$ para otros cultivos, las 
cuales están distribuidas por todo el país en pequeñas parcelas. Sin embargo la producción nacional no es suficiente para la demanda local, prueba de esto es que las importaciones superan por mucho a las exportaciones, presentando un déficit comercial en este sector (Cuadro 2.7).

\section{Cuadro 2.7}

Exportaciones e importaciones de productos agrícolas (miles de dólares)

\begin{tabular}{|c|c|c|c|c|c|c|}
\hline \multirow{2}{*}{$\begin{array}{l}\text { Concepto } \backslash \\
\text { Año }\end{array}$} & \multicolumn{2}{|c|}{2005} & \multicolumn{2}{|c|}{2006} & \multicolumn{2}{|c|}{2007} \\
\hline & Exportación & Importación & Exportación & Importación & Exportación & Importación \\
\hline $\begin{array}{l}\text { Legumbres y } \\
\text { hortalizas }\end{array}$ & 9,160 & 61,657 & 10,454 & 65,913 & 12,744 & 61,349 \\
\hline $\begin{array}{l}\text { Frutos } \\
\text { comestibles }\end{array}$ & 2,413 & 46,513 & 2,673 & 48,097 & 3,178 & 51,673 \\
\hline $\begin{array}{l}\text { Granos } \\
\text { básicos }\end{array}$ & 406 & 132,436 & 731 & 161,740 & 2,870 & 223,858 \\
\hline
\end{tabular}

Fuente: Elaboración propia a partir de datos del BCR

Por otra parte, la participación que estas exportaciones tienen en el
PIB es insignificante (Cuadro 2.8), ya que no alcanza ni el $1 \%$.

\section{Cuadro 2.8}

Participación de las exportaciones de productos agrícolas en el PIB

\begin{tabular}{lccc}
\hline \multicolumn{1}{r}{ Concepto $\backslash$ Año } & $\mathbf{2 0 0 5}$ & $\mathbf{2 0 0 6}$ & $\mathbf{2 0 0 7}$ \\
\hline Legumbres y Hortalizas & $0.0537 \%$ & $0.0560 \%$ & $0.0626 \%$ \\
Frutos comestibles & $0.0141 \%$ & $0.0143 \%$ & $0.0156 \%$ \\
Granos básicos & $0.0024 \%$ & $0.0039 \%$ & $0.0141 \%$ \\
\hline
\end{tabular}

Fuente: Elaboración propia a partir de datos del BCR

Distribución de la producción agrícola en el territorio (maíz, frijol y sorgo)

La mayor producción de maíz, frijol y sorgo se realiza en la zona paracentral del territorio salvado- 


\section{Cuadro 2.9 \\ Producción de granos básicos (maíz, sorgo, frijol) en la zona paracentral} (2005-2006)

\begin{tabular}{lcc}
\hline \multicolumn{1}{r}{ Departamento } & Producción QQ & \% del total \\
\hline Chalatenango & $1,772,583$ & $19.59 \%$ \\
\hline Cabañas & 943,615 & $10.43 \%$ \\
\hline Cuscatlán & 911,186 & $10.07 \%$ \\
\hline San Vicente & $1,316,162$ & $14.55 \%$ \\
\hline La Paz & 935,942 & $10.34 \%$ \\
San Salvador & $1,353,895$ & $14.96 \%$ \\
La Libertad & $1,814,066$ & $20.05 \%$ \\
Total & $\mathbf{9 , 0 4 7 , 4 4 9}$ & $\mathbf{1 0 0 . 0 0 \%}$ \\
\hline
\end{tabular}

Fuente: Elaboración propia a partir de datos de la Digestyc

Para la zona de occidente la distribución de la producción es uniforme. Esta produce el 29.08\% del total, en donde Ahuachapán,
Santa Ana y Sonsonate producen el $10.36 \%, 10.60 \%$ y $8.12 \%$ respectivamente (Cuadro 2.10).

\section{Cuadro 2.10}

Producción de granos básicos (maíz, sorgo, frijol) en la zona occidental (2005-2006)

\begin{tabular}{lc}
\hline \multicolumn{1}{c}{ Departamento } & Producción QQ \\
\hline Ahuachapán & $2,106,842$ \\
Santa Ana & $2,155,342$ \\
Sonsonate & $1,650,736$ \\
\hline Total & $\mathbf{5 , 9 1 2 , 9 2 0}$ \\
\hline
\end{tabular}

Fuente: Elaboración propia a partir de datos de la Digestyc

La zona oriental participa con el $26.43 \%$ del total de la producción y en donde el departamento de Usulután es el que más produce en esta zona con el $14.94 \%$. La Unión,
San Miguel y Morazán son los que menos participan con el $3.74 \%$, $5.12 \%$ y el $2.62 \%$ respectivamente (Cuadro 2.11). 
Cuadro 2.11

Producción de granos básicos (maíz, sorgo, frijol) en la zona oriental (2005-2006) por quintales

\begin{tabular}{lr}
\hline \multicolumn{1}{c}{ Departamento } & Producción \\
\hline La Unión & 760,570 \\
San Miguel & $1,041,090$ \\
Morazán & 533,004 \\
Usulután & $3,038,720$ \\
Total & $\mathbf{5 , 3 7 3 , 3 8 4}$
\end{tabular}

Fuente: Elaboración propia a partir de datos de la Digestyc

Estos resultados nos indican que la zona donde más se cultiva es la zona paracentral con un $44.49 \%$, luego la zona de occidente con un $29.08 \%$ y por último la zona de oriente con un $26.43 \%$. La razón por la cual se tiene un déficit en este sector es que el uso que se les da no va de acuerdo con la vocación del suelo; es decir que las tierras que son más aptas para el cultivo, no son usadas para este fin $y$ las tierras que tienen menos vocación tienen un uso intensivo (Cuadro 2.12), por lo tanto eso resta la productividad de las tierras.

\section{Cuadro 2.12}

Vocación de las tierras según región

\begin{tabular}{cc}
\hline Región & $\begin{array}{c}\text { Tierras excelentes para cultivos de } \\
\text { granos básicos (hectáreas) }\end{array}$ \\
\hline Región paracentral & 1117 \\
\hline Región occidental & 2903 \\
\hline Región oriental & 9713 \\
\hline
\end{tabular}

Fuente: MAG, 2006

Claramente las tierras de la región oriental son las que tiene mayor vocación para los cultivos, sin embargo la producción de esta región es del $26.43 \%$. Por otro lado, la región paracentral es la que mayor participación en la producción nacional tiene, donde se presenta menor vocación para cultivar.

\subsection{Análisis intersectorial}

La Matriz Insumo Producto (MIP) ilustra las interrelaciones entre los diversos sectores productivos de un país, transacciones intermedias y demanda final. A partir de la MIP se pueden analizar los vínculos entre los distintos sectores y la participación de cada sector a la economía. 
Cabrera Melgar (2005) determinó los sectores claves en la economía salvadoreña a partir de la MIP. Cabrera hace uso de dos índices: Poder de Dispersión (PD) y Sensibilidad de Dispersión (SD). El primero mide el impulso que todos los sectores logran a partir del estímulo de un sector en particular, funcionando como un multiplicador de la producción; y el segundo, mide el impulso de un sector ante el estímulo de todos los sectores de la economía funcionando como multiplicador de la demanda. Según el valor que tomen estos coeficientes existen cuatro clasificaciones, como lo muestra el Cuadro 2.13

\section{Cuadro 2.13}

\section{Aspectos teóricos sobre la clasificación de los sectores y ramas económi-} cas según los coeficientes SD y PD.

\begin{tabular}{|c|c|c|}
\hline SD & PD & Clasificación del sector \\
\hline Mayor que 1 & Mayor que 1 & $\begin{array}{l}\text { Clave: dependen en su mayoría del conjunto de la } \\
\text { economía. Son sectores que cuando se produce un } \\
\text { incremento en la demanda final de algún otro sector, éstos } \\
\text { requieren en términos relativos de más insumos que el } \\
\text { resto, pues son insumos intermedios de los primeros. }\end{array}$ \\
\hline Mayor que 1 & Menor que 1 & $\begin{array}{l}\text { Estratégico: sectores que requieren de una cantidad mínima } \\
\text { de insumos, siendo su producción más bien intermedia } \\
\text { que final. }\end{array}$ \\
\hline Menor que 1 & Mayor que 1 & $\begin{array}{l}\text { Impulsores: son sectores importantes ya que demandan } \\
\text { insumos de otros sectores intermedios, la producción } \\
\text { global se ve muy influenciada por lo que en éstos ocurra. }\end{array}$ \\
\hline Menor que 2 & Menor que 1 & $\begin{array}{l}\text { Islas: son sectores poco atractivos en términos de provocar } \\
\text { un mayor impacto en la economía, pues su desarrollo no } \\
\text { afecta en demasía a los sectores que son insumo de éstos, } \\
\text { ni a los que emplean a éstos como productos intermedios. }\end{array}$ \\
\hline
\end{tabular}

Fuente: La heterogeneidad estructural y la dinámica laboral en El Salvador (tesis), 2006.

\section{La Matriz Insumo Producto} de El Salvador está conformada por 45 ramas económicas, 11 formando parte del sector primario, 21 del sector secundario y 13 del sector terciario. La matriz es una herramienta para conocer el funcionamiento y nivel de articulación de la economía, por lo que no se puede demostrar un problema de concentración geográfica. Puede ser de gran ayuda la distribución que se da en los sectores (primario, secundario y terciario) en la matriz, es así como el sector primario se ubica por lo general en el campo y no presenta un mayor interrelación entre el sector secundario y terciario; mostrando una gran cantidad de casillas en blanco. Las ramas del sector primario son islas a excepción de la avicultura, debido a la falta de una adecuada articulación de los sectores. 
Para el sector secundario, las ramas que se presentan como estratégicas son la producción de molinería, otros productos de alimentos elaborados, textiles, producción de la imprenta, producción de refinerías de petróleo y producción de caucho y plástico. Las ramas que se presentan como claves son las de química y elaborados, productos metálicos, construcción, maquinaria, equipos y suministros y materiales de transporte y manufacturas diversas. Al verificar las cantidades demandadas por otras ramas, se puede observar un cierto nivel de articulación o interrelación entre las ramas. Pero, al hacer uso de los porcentajes de producción que se genera en cada departamento para cada una de las ramas, no se puede dejar de lado la idea de una rama productiva interrelacionada, pero si se ven ramas productivas estratégicas o claves las cuales generan su mayor porcentaje de producción en los departamentos de San Salvador y La Libertad.

\section{Cuadro 2.14}

\section{Clasificación de las ramas económica según sector y rama.}

\begin{tabular}{|c|c|c|c|c|c|}
\hline \multirow{2}{*}{ Sector } & \multirow{2}{*}{ Rama } & \multicolumn{4}{|c|}{ Clasificación } \\
\hline & & Clave & Estratégico & Isla & Impulsor \\
\hline \multirow{11}{*}{$\begin{array}{c}\text { Sector } \\
\text { Primario }\end{array}$} & 1.Café oro & & & $x$ & \\
\hline & 2.Algodón & & & $x$ & \\
\hline & 3.Granos básicos & & & $x$ & \\
\hline & 4.Caña de azúcar & & & $x$ & \\
\hline & 5.Otras prod. agrícolas & & & $x$ & \\
\hline & 6.Ganadería & & & $x$ & \\
\hline & 7.Avicultura & & & & $x$ \\
\hline & 8.Silvicultura & & & $x$ & \\
\hline & 9.Prod. de la caza y pesca & & & $x$ & \\
\hline & 10.Prod. de la minería & & & $x$ & \\
\hline & 11.Carne y sus productos & & & $x$ & \\
\hline \multirow{10}{*}{$\begin{array}{c}\text { Sector } \\
\text { Secundario }\end{array}$} & 12.Prod. Lácteos & & & $x$ & \\
\hline & 13.Prod. Elaborados de la pesca & & & $x$ & \\
\hline & 14.Prod. De molinería & & $X$ & & \\
\hline & 15.Azúcar & & & $x$ & \\
\hline & 16.Otros prod. Alim. Elaborados & & $x$ & & \\
\hline & 17.Bebidas & & & $x$ & \\
\hline & 18.Tabaco elaborado & & & $x$ & \\
\hline & 19. Textiles y art. Confec de mat. Text. & & $x$ & & \\
\hline & 20.Prendas de vestir & & & $X$ & \\
\hline & 21.Cuero y sus productos & & & $x$ & \\
\hline
\end{tabular}




\begin{tabular}{|c|c|c|c|c|c|}
\hline \multirow{2}{*}{ Sector } & \multirow{2}{*}{ Rama } & \multicolumn{4}{|c|}{ Clasificación } \\
\hline & & Clave & Estratégico & Isla & Impulsor \\
\hline \multirow{11}{*}{$\begin{array}{l}\text { Sector } \\
\text { Secundario }\end{array}$} & 22. Madera y sus prod. & & & $x$ & \\
\hline & 23.Papel, cartón y sus productos & & & $x$ & \\
\hline & $\begin{array}{l}\text { 24.Prod. De la imprenta y de ind. } \\
\text { Conex. }\end{array}$ & & $\mathrm{x}$ & & \\
\hline & 25.Química de base y elaborados & $X$ & & & \\
\hline & 26.Prod. De la refinería de petróleo & & $\mathrm{X}$ & & \\
\hline & 27.Prod. De caucho y plástico & & $x$ & & \\
\hline & 28.Prod. De minerales no metálicos & & & $\mathrm{x}$ & \\
\hline & 29.Prod. Metálicos de base y elab. & $x$ & & & \\
\hline & 30.Construcción & $x$ & & & \\
\hline & 31. Maquinaria, equipos y suministros & $X$ & & & \\
\hline & $\begin{array}{l}\text { 32.Material de Transp. Y manuf. } \\
\text { Diversas }\end{array}$ & $x$ & & & \\
\hline \multirow{13}{*}{$\begin{array}{l}\text { Sector } \\
\text { Terciario }\end{array}$} & 33.Electricidad & & & $\mathrm{x}$ & \\
\hline & 34.Agua y alcantarillados & & & $x$ & \\
\hline & 35.Comercio & & & & $x$ \\
\hline & 36. Restaurantes y hoteles & $x$ & & & \\
\hline & 37.Transp. Y almacenamiento & $x$ & & & \\
\hline & 38.Comunicaciones & & $\mathrm{X}$ & & \\
\hline & 39.Bancos, seguros y otras inst. & & & $x$ & \\
\hline & 40.Bienes inmuebles y serv. Prestados & & & $x$ & \\
\hline & 41.Alquileres de viviendas & $X$ & & & \\
\hline & 42.Serv. Comunales, sociales y pers. & & $\mathrm{X}$ & & \\
\hline & 43.Servicios domésticos & & & $x$ & \\
\hline & 44.Servicios de gobierno & $x$ & & & \\
\hline & 45.Servicios industriales & $x$ & & & \\
\hline
\end{tabular}

Fuente: elaboración propia a partir de datos contenidos en Heterogeneidad estructural y la dinámica laboral en El Salvador (tesis), 2006.

Para el sector terciario las ramas islas son la electricidad, agua, bancos y seguros, bienes inmuebles y servicios domésticos. La única rama que se presenta como impulsora es el comercio y las claves son los restaurantes y hoteles, trasporte y almacenamiento, servicios de gobierno y los servicios industriales. Las ramas estratégicas son comunicaciones y los servicios comunales.
El sector terciario puede presentar un nivel de crecimiento en sus ramas estratégicas e impulsoras, pero este crecimiento no es articulado a las demás ramas de la económica.

El sector terciario presenta ramas de producción claves y estratégicas, pero estas estarán perfiladas a la búsqueda de crecimiento ubicándose en focos de desarrollo 
habitacional o de inversión, con el objetivo de facilitar el acceso a segmentos de demanda que presenten mayor capacidad de compra. En el sector terciario no se encuentran ramas articuladas, que generen un incremento de cantidades demandadas $u$ ofertadas entre las demás ramas del sector primario y secundario.

\subsubsection{Sectores productivos y des- equilibrios territoriales}

La MIP permite realizar un análisis a la estructura productiva salvadoreña a través de los encadenamientos de las diferentes ramas productivas. Para este estudio se han tomado en cuenta los sectores de la matriz presentados en el cuadro 2.15, relacionando estos sectores de la matriz con las actividades del Censo económico 2005. El objetivo de esta relación es hacer uso de los porcentajes de producción de cada actividad productiva que permitan determinar los desequilibrios departamentales según los sectores en la matriz insumo producto, una vez descritos los desequilibrios territoriales según la organización político administrativa de El Salvador y sus departamentos, se busca evidenciar cómo la desarticulación del aparato productivo de la economía salvadoreña afecta aún más los desequilibrios económicos territoriales.

\section{Cuadro 2.15}

\section{Relación entre sectores de la matriz y actividades del censo económico}

\begin{tabular}{l|ll}
\hline \multicolumn{1}{c|}{ Sector MIP } & \multicolumn{2}{c}{ Actividad Censo } \\
\hline 10 Minería & 14 & Explo. De otras minas y canteras \\
\hline 16 Otros prod. alimenticios elaborados & 15 & Elab. de productos alimen. y bebida \\
\hline 17 Bebidas & 16 & Elab. productos de tabaco \\
\hline 19 Tabaco & 17 & Fab. de productos textiles \\
\hline 20 Prendas de vestir & 18 & Fab.prend.vestir, adobo y teñ.piel \\
\hline 21 Cuero y sus productos & 19 & Curt.adobo de cuero,product.talabar \\
\hline 22 Madera y sus productos & 20 & Fab.Product.mader,paja y mat.tren \\
\hline 23 Papel, cartón y sus productos & 21 & Fab. de papel y productos de papel \\
\hline 24 Imprentas e industrias conexas & 22 & Acts.edic.e impre.y reproducc.graba \\
\hline 25 Productos químicos & 24 & Fab. de sustancias y prod. químicos \\
\hline 26 Prod. de la refinería de petróleo & 23 & Fab.de product.refin.petrol. y comb \\
\hline 27 Productos de caucho y plásticos & 25 & $\begin{array}{l}\text { Fabricación de productos de caucho y } \\
\text { plástico }\end{array}$ \\
\hline 28 Productos minerales no metálicos & 26 & $\begin{array}{l}\text { Fabricación de otros productos minerales no } \\
\text { metálicos }\end{array}$ \\
\hline
\end{tabular}




\begin{tabular}{|c|c|c|}
\hline Sector MIP & & Actividad Censo \\
\hline 29 Productos metálicos & 27 & Fabricación de metales comunes \\
\hline 30 Maquinaria, equipo y suministros & 29 & Fabricación de maquinaria y equipo \\
\hline 31 Material de transporte & 34 & $\begin{array}{l}\text { Fabricación de vehículos automotores, } \\
\text { remolques y semirremolques }\end{array}$ \\
\hline 34 Construcción & 4520 & Construc.edificios,obras ing.civil \\
\hline 35 Comercio & 51 & Comercio al por mayor y en comisión \\
\hline 36 Restaurantes y hoteles & 55 & Hoteles y restaurantes \\
\hline 38 Comunicaciones & 64 & Correo y Telecomunicaciones \\
\hline 39 Bcos, seguros y otras inst. financieras & & $\begin{array}{l}\text { Intermediación financiera excepto la } \\
\text { financiación de planes de seguros y de } \\
\text { pensiones }\end{array}$ \\
\hline 41 Alquileres de viviendas & 70 & Actividades inmobiliarias \\
\hline
\end{tabular}

Fuente: elaboración propia a partir de la MIP y del censo económico.

Si se miden los sectores según su producción, los principales sectores resultan ser construcción, alquiles de viviendas, restaurantes y hoteles, bancos y seguros, bienes inmuebles, productos alimenticios, productos químicos y textiles.

De estos sectores, el sector transporte, construcción, alquiler de viviendas, restaurante y hoteles y productos químicos son sectores claves. El sector de producción de alimentos elaborados y textiles son sectores estratégicos. Los únicos sectores que poseen un alto nivel de producción y que son sectores isla son los bancos y seguros y bienes inmuebles.

Por lo otro lado, se observa cómo cambia el nivel de interrelación entre el sector secundario y terciario con respecto a la demanda que posee cada una de las ramas entre estos sectores (anexo 1), pero la producción que estos sectores poseen se realiza en la zona central y paracentral del país, como se puede ver en el cuadro 2.13; mostrando la existencia de concentración geografía y concentración de sus interrelaciones.

Para generar una matriz que muestre la demanda de cada departamento según los sectores de producción que se han tomado en cuenta, se ha hecho uso de los porcentajes de la producción bruta por departamento para cada actividad del censo, con lo que resulta una matriz territorial que se presenta en el anexo 2 y 3 cuyos resultados abreviados se presentan en el cuadro 2.16, se puede observar el desequilibrio económico territorial en función de los porcentajes de producción de cada departamento para cada sector. 
Para el caso de la industria textilera, elaboración de otros productos de alimentos y bebidas, cueros y sus productos, producción de papel y cartón, producción de imprenta, productos químicos, producción de caucho y plástico, productos metálicos, maquinaria y equipos, construcción, comercio, bancos y otras instituciones financieras y alquiler de vivienda los departamentos de San Salvador y la Libertad generan más del $80 \%$ de la producción para cada una de estos sectores, por lo que pueden haber ramas o actividades denominadas como claves o estratégicas según sus coeficientes SD y PD, pero es importante que las ramas interactúen a nivel sectorial y posean actividad productiva regional; posibilitando una mayor articulación de la cadena productiva y un impacto en la generación de empleos a nivel nacional.

Para los sectores de producción minera, madera, prendas de vestir, tabaco y producción de refinería de petrolera cambia el patrón centralizador de la producción. Tanto para la producción de minerales no metálicos y prendas el departamento de La Paz produce un $15.50 \%$ y $15.93 \%$ respectivamente. Sonsonate produce el $97.90 \%$ de la producción de refinería de petróleo y San Miguel produce el $20.58 \%$ de la producción de tabaco, como aparece en el cuadro 2.16. 


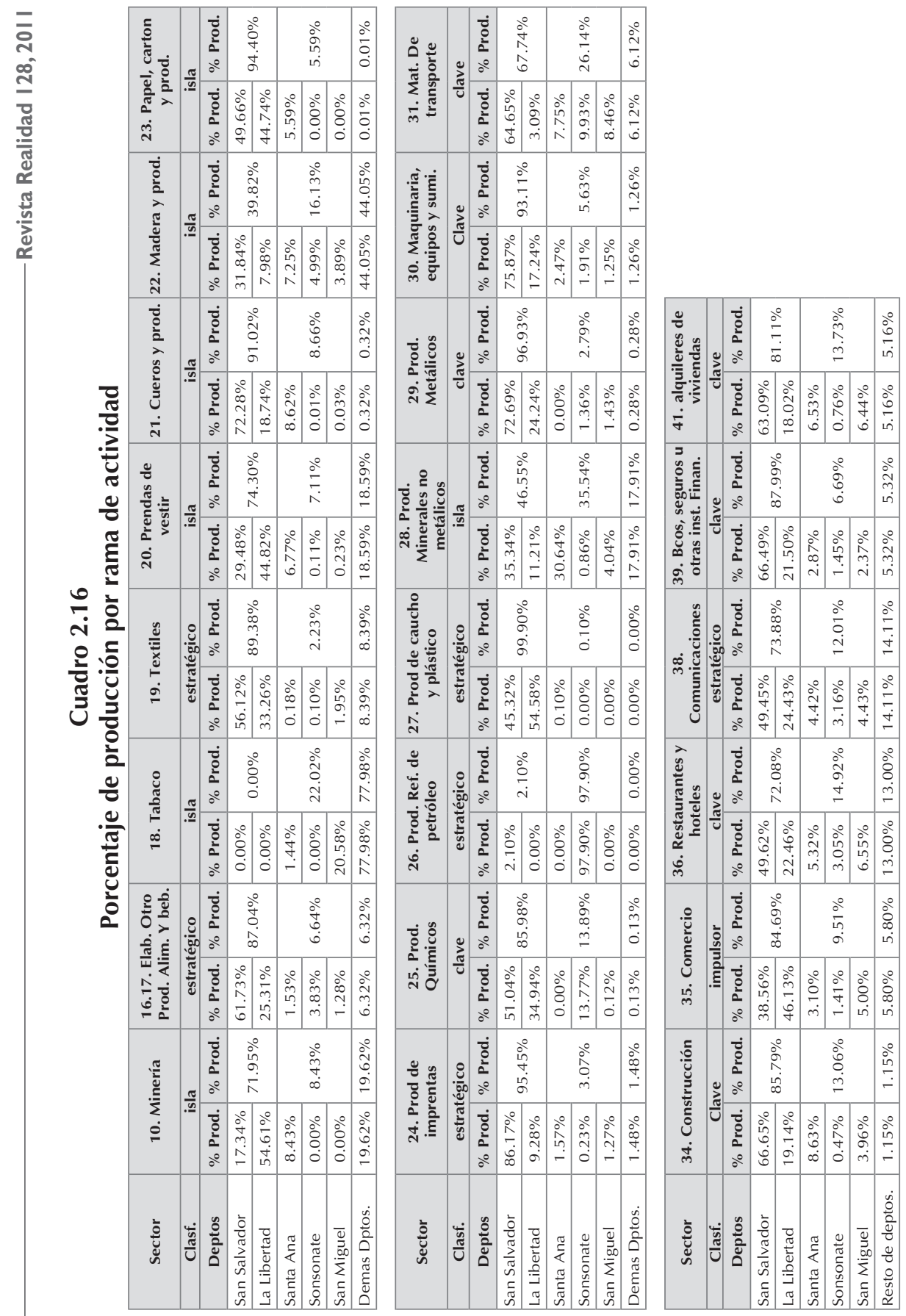




\subsubsection{Desarticulación sectorial}

La desarticulación sectorial se puede entender como la incapacidad que tiene la economía de producir un efecto cadena en el crecimiento económico de los sectores, es decir, cuando hay crecimiento en un sector, no teniendo como consecuencia el crecimiento y mayor producción en los demás sectores que conforman la economía.

Para algunos expertos, como Roberto Rubio, la economía cuenta con sectores que no son protagonistas del crecimiento económico pero que deberían de dárseles mayor importancia por ser claves para la economía "como el sector agropecuario y la industria manufacturera articulada al mercado interno (e incluso centroamericano), continúan en una situación de práctico estancamiento. Adicionalmente, son cada vez menos evidentes y posibles los niveles de articulación de los sectores productivos" (Rubio, 2001).

Rubio (2001) atribuye la desarticulación sectorial en buena medida a los Programa de Ajuste Estructura (PAE), Ilevados a cabo a inicios de la década pasada por el Estado salvadoreño y que tuvieron importantes consecuencias en la formulación del modelo económico actual. Luego de la aplicación de estas medidas, se dio menos importancia al mercado interno, en su lugar, las políticas y programas de crecimiento sugirieron priorizar los mercados externos o "hacia ciertos mercados internos 'verticales' con alto poder de compra" (Rubio, 2001). Las políticas públicas y de inversión privada no tomaron en cuenta al mercado interno, hubo bajo gasto público, bajos incrementos salariales y falta de programas de empleo y de articulación sectorial que "ha venido jugando en contra de la misma dinamización del aparato productivo nacional, y por ende se ha llegado a convertir en un serio obstáculo a los intentos de generar altas tasas de crecimiento económico" (Rubio, 2001).

Por otra parte, la poca planeación en torno a las políticas sectoriales que más convenían al país contribuyó a la desarticulación sectorial. "Los enfoques y políticas provenientes de los PEE/PAE no sólo abandonaron el mercado interno sino también los esfuerzos de planeación y de formulación de políticas sectoriales." (Rubio, 2001). En lugar de fomentar políticas de crecimiento en los sectores más importantes y de beneficio para la mayor parte de la sociedad, se hizo un esfuerzo por mejorar el mercado de capitales y de las finanzas. "El abandono de estas últimas eran congruentes con una política económica que concentraba los esfuerzos en el sector moderno de las finanzas, el comercio y la exportación, y dejaba a los "naturales desbordes" de estos sectores la reactivación del agro, la 
industria manufacturera integrada al mercado nacional, y en cierto sentido también la dinamización del sector de la construcción" (Rubio, 2001).
A nivel centroamericano, los sectores a los que se le dio importancia no trasladaron su crecimiento al sector agropecuario y manufacturero local, al contrario,

"para una gran cantidad de productores agrícolas centroamericanos, el ajuste y la reestructuración no se limitan a desbaratarlos, sino que más bien los eliminan. La producción y los "espacios" disponibles en el mercado dentro del ajuste y la reestructuración son limitados y desiguales" (Judson, 1998).

Los sectores primarios se vieron relegados por los sectores terciarios: "quedaron afectados por sus modernas operaciones: importaciones a bajo precio que desplazaron productores locales, altos costos financieros, orientación preferencial del crédito hacia actividades de más corto plazo y menor riesgo, etc." (Rubio, 2001). El moderno mercado financiero con el que cuenta la región ha sido en parte responsable del olvido en el que están los demás sectores de la economía. Esto afecta las posibilidades de un crecimiento y desarrollo económico equilibrado para la sociedad. "Los criterios de crédito dictados por el mercado financiero suelen favorecer a los productores mayores, más eficientes y más rentables" (Judson, 1998). Las actividades que no son consideradas productivas no reciben créditos que pudieran ayudarles a mejorar sus tecnologías y aumentar su productividad. En estas circunstancias es aún más difícil que estos sectores solucionen sus problemas de eficiencia.

Existe un grupo de personas y empresas que no percibieron los beneficios de los PAE puesto que fueron excluidos de la distribución de las ganancias,

"el ajuste y los Programas de Ajuste Estructural agudizan la marginación. Dicho sencillamente, la lógica del neoliberalismo inevitablemente crea una población sobrante, gente con poco o ningún papel en el mercado, cuya labor y consumo no son necesarios para el funcionamiento "eficiente" de las economías reestructuradas" (Judson, 1998).

Esta desarticulación sectorial, problema estructural, es responsa- ble en parte de los desequilibrios territoriales que se viven en el país. 


\section{Desequilibrios económicos territoriales: Causas}

Una causa de los desequilibrios económicos territoriales es el funcionamiento estructural de la economía salvadoreña, es decir la tendencia a concentrar el desarrollo en una determinada zona. Prueba de ello es que una gran cantidad de bienes y servicios sólo se obtienen en el Área Metropolitana de San Salvador (AMSS), la cual está conformada por catorce municipios concentrados en sólo dos departamentos.

Del total de establecimientos de El Salvador, el $40.18 \%$ se encuentra en el AMSS, esto se traduce en un 58.64\% del total de empleos en El Salvador. Por lo tanto es obvia la importancia que tiene el AMSS para la economía salvadoreña.

Como consecuencia, los tres sectores con mayor participación en la economía poseen un porcentaje muy considerable de participación en el AMSS, lo que repercute en que también el AMSS participe considerablemente en el total de acción según rama de actividad económica.

\section{Cuadro 3.1}

\section{Participación en la AMSS y por rama de actividad económica}

\begin{tabular}{lcc}
\hline \multicolumn{1}{c}{ Sector } & $\begin{array}{c}\text { \% de participación en el } \\
\text { AMSS }\end{array}$ & $\begin{array}{c}\text { \% de participación por rama de } \\
\text { actividad económica }\end{array}$ \\
\hline Comercio & $61.43 \%$ & $37.40 \%$ \\
Servicios & $22.06 \%$ & $48.20 \%$ \\
Industria & $40.10 \%$ & $12.98 \%$ \\
\hline
\end{tabular}

Fuente: Elaboración propia, a partir de datos del VII Censo Económico 2005

Esta concentración de actividades económicas en el AMSS generan oferta de bienes y servicios que contribuyen al aumento de ingresos de las personas que habitan la región del AMSS, esto aunado a que un porcentaje considerable de la población habita en el AMSS (el 27.27\% según el VI censo de población y $\mathrm{V}$ Vivienda 2007), provoca un nivel adecuado de demanda, el que a su vez puede estimular la creación de nuevos bienes o servicios, y con ello se obtendrán mayores beneficios. Esto puede comprobarse en los datos proporcionados por el VII Censo Económico 2005, donde se especifica que San Salvador y La Libertad participan con el $73.43 \%$ del total de "valor de la venta y otros ingresos de operación."

Por lo tanto, podemos afirmar que el afán o la búsqueda racional que los empresarios tienen por 
maximizar ganancias es causa de desequilibrios económicos territoriales, ya que estos tenderán a agruparse o concentrarse en regiones donde existan condiciones que les permitan maximizar sus beneficios, como suficiente oferta de trabajo, recursos naturales, mano de obra calificada y no calificada.

Esta es causa de desequilibrios, dado que las oportunidades son mayores y mejores en el AMSS, debido a que la mayoría de áreas de actividad económica se encuentran concentradas, provocando una situación de desventaja para las zonas restantes, ya que factores como la distancia a la zona central es un claro impedimento a obtener bienes, servicios, empleo, etc.

Un elemento que refuerza el desarrollo de la zona del AMSS y que por ello puede considerarse como causa de desequilibrios económicos territoriales, es la decisión que tomen las empresas con respecto a su localización. La ubicación de las empresas puede constituir un desequilibrio económico, ya que al ubicarse una gran cantidad en una zona específica (en este caso en el AMSS), esto repercute en aspectos importantes tales como el empleo. Esto puede comprobarse mediante los datos reflejados en el VII Censo Económico 2005, ya que del total de ocupados $(699,581)$, el $62.83 \%$ se encuentra en el AMSS.
La razón por la cual las empresas tienden a concentrarse en el AMSS es porque buscan maximizar beneficios, reducir costos, tener acceso a recursos naturales, tecnológicos, humanos, existencia de demanda que puede absorber su oferta, etc. Esto es posible en el AMSS ya que la mayoría de actividades económicas y una gran parte de la población se encuentran en dicha zona.

Esta situación es más grave de lo que parece, ya que para invertir se buscarán las mejores condiciones posibles, las cuales ofrece en mejor forma el AMSS en relación a las zonas restantes. Surge entonces una consecuencia muy grave de este desequilibrio: Si se piensa invertir en zonas con poco desarrollo (en relación con el AMSS), con el objeto de disminuir los desequilibrios, esto se vuelve muy difícil, ya que va en contra de la naturaleza de las condiciones necesarias para inversión, por lo tanto, es complicado invertir en zonas donde los recursos sean mucho menores a los del AMSS.

Esto está muy relacionado con la racionalidad capitalista que opera en la economía. La composición orgánica de capital, en donde el capital se compone de medios de producción (maquinaria, materia prima, tecnología, etc.), y de trabajo vivo (fuerza de trabajo de cada individuo). A su vez, los medios de 
producción constituyen el capital constante (CC) mientras que la fuerza de trabajo constituye el capital variable $(\mathrm{CV})$.

La relación entre capital constante y capital variable mide el nivel técnico que posee una rama de actividad económica, una industria, una empresa, etc. Esto provoca que los capitalistas, en la búsqueda de maximizar sus beneficios, se empeñen en aumentar la composición orgánica del capital, es decir obtener un mayor grado de tecnificación, lo que se traduce en un incremento de medios de producción ante una gran disminución de trabajo vivo, marginando a aquellos sectores que cuenten con una composición orgánica de capital más intensiva en capital variable que en capital constante $y$, por ende, se excluye a las personas que se desenvuelven en dichos sectores.

Es en esta búsqueda de un mayor nivel de ganancias es que se produce la desnacionalización de empresas, ya que se necesitan recursos innovadores, avances tecnológicos sofisticados, mayores conocimientos; y estos se encuentran en el extranjero debido al mayor nivel de desarrollo tecnológico alcanzado. Al ocurrir esta desnacionalización se refuerza la tendencia a la concentración y centralización del capital provocada por fusiones entre empresas, monopolios, oligopolios, etc., a la vez que la propiedad del capital deja de ser de origen exclu- sivamente nacional. Todos estos son elementos constituyentes de desequilibrios económicos territoriales, ya que existirá una tendencia a concentrar en zonas específicas las ganancias y beneficios derivados de la acumulación del capital.

Otra causa de los desequilibrios económicos territoriales es la desarticulación de la economía salvadoreña. En el AMSS se encuentra la gran mayoría de sectores, la mayor producción, el mayor número de establecimientos, etc. Esto significa que no se necesita en gran manera insumos provenientes de los departamentos restantes, provocando el aislamiento de las actividades económicas realizadas fuera del AMSS.

Esto puede comprobarse al realizar un análisis entre los encadenamientos de las ramas productivas, el cual se ha desarrollado en el numeral 2.3, donde se utilizaron los porcentajes de producción de cada actividad productiva para identificar los desequilibrios económicos departamentales según los sectores presentados.

Un elemento que contribuye a profundizar la desarticulación sectorial es la ausencia de políticas sectoriales, con lo cual sobreviven aquellos sectores que cuentan con operaciones modernas, que tienen más acceso a créditos, siendo en parte responsable el moderno mercado financiero ya que se da cierta orientación preferencial de créditos 
hacia aquellas actividades de más corto plazo y menor riesgo, relegando a los sectores primarios, ya que estos al ser considerados como actividades poco productivas, el otorgamiento de los créditos favorecerán a las actividades económicas más eficientes y rentables.

Otro elemento que refuerza los desequilibrios económicos territoriales es el de ganancia en los sectores y los valores de venta en sus operaciones. Si la brecha de ganancia entre ramas de actividad económica es muy grande, las zonas especializadas en esos sectores tenderán a desaparecer y con ello los desequilibrios serán también a nivel regional y no sólo por sectores de actividad económica. En el cuadro 3.4 se observa el porcentaje de valor de la venta y otros ingresos de operación, siendo este el resultado de las ganancias con que cuenta cada sector. Esto hace posible identificar los desequilibrios económicos territoriales.

\section{Cuadro 3.2}

Establecimiento, Valor de Venta y Otros Ingresos de Operación

\begin{tabular}{lrrr}
\hline \multirow{2}{*}{ Ramas de Actividad Económica } & \multicolumn{2}{c}{ Establecimientos } & $\begin{array}{c}\text { Valor de la venta y } \\
\text { otros ingresos de } \\
\text { operación }\end{array}$ \\
\cline { 2 - 4 } Minas y canteras & \multicolumn{1}{c}{ cantidad } & porcentaje & $0.02 \%$ \\
\hline Agroindustria & 8.00 & $0.005 \%$ & $1.63 \%$ \\
\hline Electricidad y agua & 71.00 & $0.041 \%$ & $4.60 \%$ \\
\hline Construcción & 79.00 & $0.045 \%$ & $1.85 \%$ \\
\hline Transporte y comunicaciones & 447.00 & $0.255 \%$ & $8.47 \%$ \\
\hline Industria & $4,065.00$ & $2.320 \%$ & $23.01 \%$ \\
\hline Servicios & $22,788.00$ & $13.008 \%$ & $15.16 \%$ \\
\hline Comercio & $32,180.00$ & $18.370 \%$ & $45.26 \%$ \\
\hline TOTAL & $115,540.00$ & $65.956 \%$ & $\mathbf{1 0 0 . 0 0} \%$ \\
\hline
\end{tabular}

FUENTE: Elaboración propia basada en el VII Censo Económico 2005

Por otro lado el estilo de crecimiento adoptado en los últimos

años también refuerza los desequilibrios económicos territoriales.

"Así, el actual modelo basado en la exportación maquilera produce notables desequilibrios dentro del país. Por ejemplo el 83\% de los 90,000 empleos generados en dicha industria se concentran en diez municipios, todos localizados en la Región Metropolitana de San Salvador (RMSS) 
(PNUD, 2003). Basta decir que la maquila de exportación se ha ubicado en solamente 33 de los 262 municipios del país, casi exclusivamente en la Región Centro Occidental del país y más específicamente en los corredores de la Carretera Panamericana, Carretera de Sonsonate / Acajutla y Autopista a Comalapa. Quiere decir que para el 2003 casi el 60\% de las exportaciones del país y el 24 de las importaciones totales (BCR, 2004), se originaron en este reducido espacio geográfico, particularmente en la RMSS" (FUNDE, 2004).

Con esto, puede explicarse parcialmente el estilo de crecimiento en la economía salvadoreña, pero es necesario conocer en qué se basa la elección de las regiones que funcionarán como polos de desarrollo.

Según la Teoría del desarrollo regional, una región se desarrollará dependiendo de las condiciones de las instituciones, la población, el transporte y comunicaciones.

Referente a la modernización de instituciones, podemos tomar como indicador la formación bruta de capital fijo. Entendiendo que a mayor inversión habrá más y me- jores instituciones, es decir que se supone una relación directa: entre más inversión mejores instituciones. En la economía salvadoreña más del $50 \%$ de la inversión de las principales ramas de actividad económica se encuentra en la zona central, específicamente en San Salvador y La Libertad, lo cual obviamente es un desequilibrio económico territorial. Un elemento más importante es la falta de institucionalidad existente, entendida como la manera en que se organizan las instituciones, sean estas públicas o privadas, ya que de esto dependen elementos como los salarios, inversión y ganancias.

"La falta de institucionalidad es un factor clave, acá me estoy refiriendo a la forma de organización de las instituciones públicas y privadas, y también de los paradigmas de desarrollo, planes, legislación, reglas etc. El capital institucional determina el cómo y el modo en que generemos y distribuyamos la riqueza. La forma y el modo de generar riqueza es la forma de cómo utilicemos los capitales (natural, tecnológico, humano, infraestructura, social), y somos capaces de generar bienes y servicios; pero también la institucionalidad determina la distribución, a través de salarios, ganancias, inversión y gasto público de esa riqueza" (Rubio, 2008) 
Cuadro 3.3

Formación bruta de capital fijo

\begin{tabular}{|lrrr|}
\hline \multicolumn{4}{c}{ FORMACION BRUTA DE CAPITAL FIJO } \\
\hline \multicolumn{1}{c}{ Departamento / Sector } & Industria & Comercio & \multicolumn{1}{c|}{ Servicios } \\
\hline San Salvador & $42.64 \%$ & $43.34 \%$ & $66.02 \%$ \\
La Libertad & $12.63 \%$ & $23.98 \%$ & $22.90 \%$ \\
Sub-total & $55.27 \%$ & $67.32 \%$ & $88.92 \%$ \\
Resto de departamentos & $44.73 \%$ & $32.68 \%$ & $11.08 \%$ \\
Total & $\mathbf{1 0 0 . 0 0} \%$ & $\mathbf{1 0 0 . 0 0} \%$ & $\mathbf{1 0 0 . 0 0} \%$ \\
\hline
\end{tabular}

FUENTE: Elaboración propia en base a VII Censo Económico 2005

El desequilibrio económico a nivel departamental es altamente reforzado por la concentración de la población en la zona central y la dotación de recursos naturales en el AMSS. Esto crea condiciones para que exista concentración de la inversión, lo que conlleva a mayores avances tecnológicos en la zona. Al haber inversión se generan empleos, elemento que contribuye a la concentración de mano de obra calificada, lo que implica que las zonas restantes queden aisladas.

Otro elemento que contribuye al aislamiento regional es el acceso que las regiones tienen (vía medios de comunicación y transporte) hacia la zona central, ya que esta constituye un polo de desarrollo. Si bien la accesibilidad a la zona central no es una causa de desequilibrios, es muy importante comprender que dificulta el desarrollo para las regiones menos avanzadas, aumentando y profundizando aún más los desequilibrios territoriales. Esto puede observarse en la figura 3.1, donde se indica la cantidad de tiempo en minutos que se necesita recorrer para acceder al AMSS. 


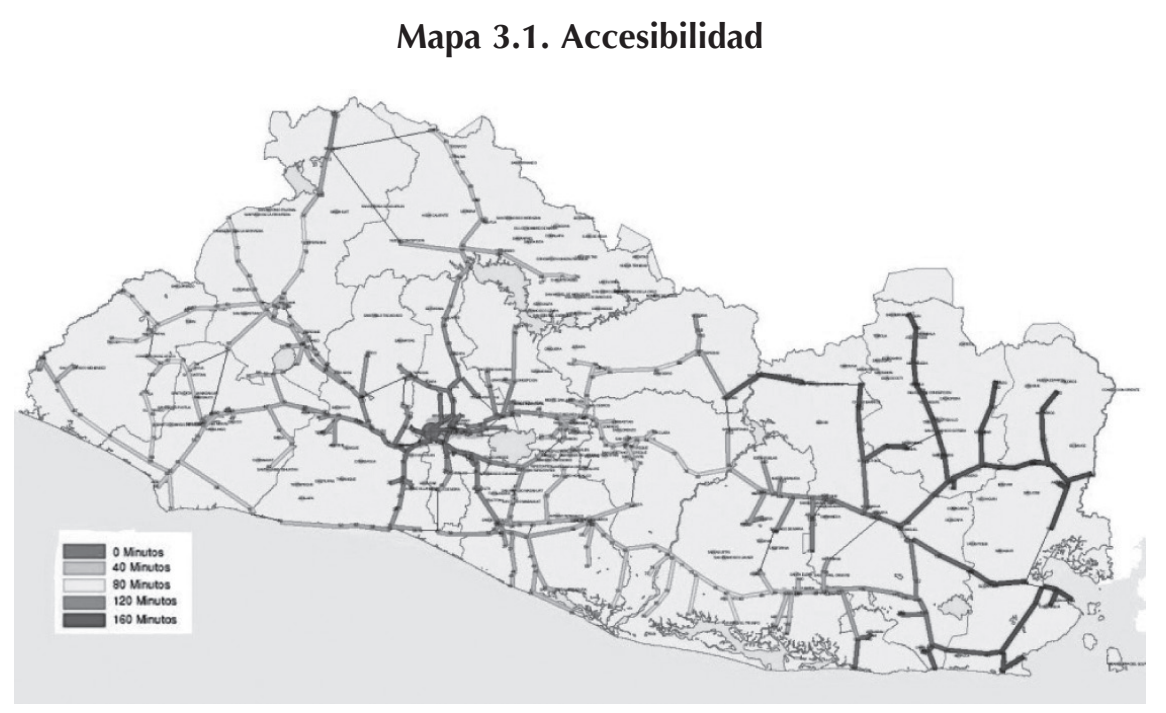

Fuente: Desequilibrios Territoriales en El Salvador. Hacia una caracterización. Ferrufino, C

La razón por la que debe tenerse accesibilidad al AMSS es por la diversidad de bienes y servicios ofrecidos, aunado a un nivel de demanda que permite el crecimiento de dicha zona. Estos son elementos que contribuyen al crecimiento de una región.
Esta condición de diversidad se cumple en el AMSS, ya que sólo en los departamentos de San Salvador y La Libertad se concentra alrededor del $50 \%$ del total de establecimientos de los principales sectores de la economía: industria, comercio, servicios. Consecuentemente, más del $50 \%$ de la producción bruta se concentra en los mismos 2 departamentos.

\section{Cuadro 3.4}

\section{Concentración de establecimientos y producción bruta}

\begin{tabular}{lcccccc}
\hline & \multicolumn{3}{c}{ Concentración de establecimientos } & \multicolumn{3}{c}{ Producción bruta } \\
\hline & INDUSTRIA & COMERCIO & SERVICIOS & INDUSTRIA & COMERCIO & SERVICIOS \\
\hline San Salvador & $38.85 \%$ & $36.68 \%$ & $44.91 \%$ & $49.47 \%$ & $44.34 \%$ & $67.07 \%$ \\
La Libertad & $10.41 \%$ & $10.36 \%$ & $11.94 \%$ & $27.88 \%$ & $24.48 \%$ & $18.61 \%$ \\
TOTAL & $\mathbf{4 9 . 2 6 \%}$ & $\mathbf{4 7 . 0 4} \%$ & $\mathbf{5 6 . 8 5} \%$ & $\mathbf{7 7 . 3 5 \%}$ & $\mathbf{6 8 . 8 2} \%$ & $\mathbf{8 5 . 6 8} \%$ \\
\hline
\end{tabular}

FUENTE: Elaboración propia en base a VII Censo Económico 2005

Lamentablemente, aunque la zona central cuente con una par- ticipación considerable en número de establecimientos y producción 
bruta, los logros alcanzados no han sido propagados en las demás zonas, todo lo contrario, los desequilibrios territoriales se refuerzan aún más.

Para solucionar esta problemática es necesario implementar algún tipo de estrategia territorial, por ello se presentarán algunos insumos que posibiliten la creación de medidas que solucionen o regulen los desequilibrios económicos territoriales.

\subsection{Insumos para una estrategia de desarrollo territorial}

Las políticas de desarrollo territorial implementadas para reducir los desequilibrios económicos territoriales no han surtido efecto, debido a que no atacan la raíz del problema. El objetivo de este apartado es ofrecer propuestas que ayuden a eliminar las causas estructurales de los desequilibrios económicos territoriales.

\subsubsection{Economía solidaria}

Ante la concentración de la riqueza, ingreso, actividades económicas en una misma zona y particularmente en un solo departamento el cual es San Salvador, nace la necesidad de cuestionarse que alternativa económica podría solventar esta problemática.

Aunque parezca difícil la mejor propuesta sería la Economía Solidaría, se dice que es difícil porque se está hablando de suprimir los sentimientos de egoísmo e individualismo aprendidos en el sistema capitalista, donde lo más importante es obtener el mayor beneficio.

"Y en una estrategia de vida alternativa, con valores distintos a los del régimen imperante, predominantemente solidaria, en tanto se actúa juntos y para todos, poniendo en evidencia el potencial de la asociatividad y cooperación" (Escobar y Zepeda, 2003: 124).

La Economía Solidaria se origina a partir de la exclusión y marginación que produce el modelo económico capitalista, en aquellas zonas que quedan aisladas de la distribución de riqueza e ingresos y en donde las actividades económicas prevalecientes son las de subsistencia. Es por eso que la Economía Solidaria toma importancia en los desequilibrios económicos territo- riales, al tratar de dar una posible solución o una alternativa al capitalismo y por lo tanto también a su racionalidad, que como se ha visto, es la causante de los desequilibrios económicos territoriales en el país. La economía solidaria teniendo una racionalidad reproductiva de la vida humana se opondría a la racionalidad de máxima ganancia del capitalismo. 
"Es pues, una organización económica donde las personas participantes (excluidos, pobres y marginados eminentemente), a partir de sus acciones, se auto-desarrollan y ganan autonomía, encontrando espacios y oportunidades en el mercado para su producción y satisfacción de necesidades" (Escobar y Zepeda, 2003: 125).

3.1.2 Mayor educación, salud y servicios básicos

La inversión en infraestructura que se está realizando en el país, como la nueva carretera Longitu- dinal del Norte, el puerto Cutuco no es necesariamente mala, ya que ayuda al desarrollo del país. Pero esta tiene que ir a la par de una mayor inversión en los servicios básicos, salud y educación.

"Está bien hacer inversión en infraestructura y eso debe mantenerse y lo que se está programando digamos que puede estar correcto puede ir en la dirección, pero es totalmente insuficiente si no hay inversión casi como compensatoria en los temas de favorecer el capital humano de estas regiones desventajadas, es decir la inversión de los servicios públicos de educación y salud en estas zonas, sino mejoramos el recurso humano que está en esas zonas no vamos a salir de gran cosa" (Ferrufino, 2008).

Gran parte de la población salvadoreña no cuenta con servicios básicos como agua potable, energía,

educación, salud; y estos son fundamentales para un desarrollo pleno de la sociedad.

"La energía en el caso hidroeléctrica que alrededor del 25\% $30 \%$ de esta energía que se consume se produce también allá en el norte del país. ¿Qué le queda a la región norte de producir eso? Nada. Sabemos que es la región que tiene menores índices de electrificación del país" (Ferrufino, 2008).

\subsubsection{Plan Nacional de Ordena- miento Territorial (PNODT)}

El ordenamiento territorial no es un tema nuevo en El Salvador, prueba de ello fueron los planes urbanísticos en las principales ciu- dades y el trabajo del Ministerio de Planificación de las décadas de los años sesenta y setenta. Pero es los últimos diez años en que la planificación y el ordenamiento territorial recuperan importancia. Es por eso que en el 2001 el Gobierno 
Central a través del Viceministerio de Vivienda y Desarrollo Urbano (VMVDU) contrató al consorcio español EPYPSA-IBERINSA para la elaboración del PNODT.

El PNODT no es visto como un fin, sino como un instrumento esencial, el cual tiene que estar articulado con otras políticas para alcanzar el desarrollo territorial. Con esto se busca retomar el desafío de la Comisión Nacional de Desarrollo (2000): "Superar la mar- ginación y exclusión estructural de grandes segmentos de la población para construir una nación integrada, estable y prospera".

Lo que se pretende es asegurar una distribución más equitativa espacialmente de las actividades humanas (económicas, de transporte, vivienda, profesionales, comercios, etc.) en todo el territorio nacional, ante la concentración de población, actividades y riqueza en el área de San Salvador.

"El Plan divide al país en tres grandes regiones: a) Centro Occidente; b) Oriente; c) Norte. Estas grandes regiones reúnen una serie de propuestas estratégicas: una visión de liderazgo de nivel centroamericano para la región Centro Occidente, una estrategia de despegue para la región Oriente y una estrategia de integración para la región Norte" (FUNDE, 2004).

A cada región le pertenece una serie de propuestas estratégicas que contribuyan a alcanzar un desarrollo territorial, las cuales incluyen: proyectos de saneamiento que mejore la calidad de vida de la población, programas de recuperación ambiental los cuales son muy importantes para el desarrollo sostenible y programas de orientación productiva. Hay que recalcar que esta es una propuesta la cual está siendo estudiada para llevarse a cabo

\subsubsection{Vivienda y asentamientos humanos}

Gran parte de la población carece de una vivienda digna. Esto se comprueba al observar las estadísticas y constatar que la mitad de la demanda habitacional está insatisfecha, prueba de esto es el proceso informal de lotificación.

"El número de hogares o familias al año 2004 se estimó en 1,626,036 con una media de miembros de 4.2 personas por grupo familiar. El parque habitacional de El Salvador al año 2004 era de 1,593,528 viviendas, de las cuales $(63 \%)$ son urbanas y $(37 \%)$ rurales. De este parque habi- 
tacional 1,081,216 (66\%) estaban en buenas condiciones y 512,312 (32\%) presentaban algún tipo de carencia o deficiencia. Si agregamos a las viviendas que presentaban deficiencias, lo correspondiente a la necesidad de nuevas viviendas, el déficit total llegaría al orden de 545,000 unidades para el año 2004. A ello habría que añadir un aproximado de 32,000 viviendas anuales debido al crecimiento vegetativo de la población" (FONAVIPO, 2005).

El mercado no es capaz de darle solución a este problema, por lo tanto es necesaria la intervención del Estado, con mayores subsidios para la vivienda social y la interven-

ción en el mercado de suelos con el objetivo de satisfacer la demanda habitacional y crear estructuras urbanas sostenibles.

"La situación actual del sector vivienda presenta grandes desafíos, principalmente en temas relativos a déficit habitacional, marco jurídico, institucionalidad, desarrollo de instrumentos y soluciones financieras de corto y largo plazo, y coordinación con otras políticas públicas. Es indispensable estructurar una política pública que, en armonía con la iniciativa privada, se proponga fortalecer la oferta habitacional y atender eficientemente la respectiva demanda. El sector no se va a desarrollar de manera mecánica: hay que potenciar su crecimiento, con visión de futuro y estímulos de presente" (FONAVIPO, 2005).

\subsubsection{Infraestructura de transporte}

El sistema vial en El Salvador está quedando obsoleto y la demanda de movilidad de personas y mercancías va aumentando, por lo que la carretera panamericana ya no es suficiente. Entre las debilidades que se pueden mencionar están el congestionamiento en su recorrido dentro del AMSS y el aislamiento de importantes zonas del país, especialmente el norte la cual es la menos desarrollada y en donde se encuentran la mayoría de municipios con mayor índice de pobreza.

"Recorrer los municipios del Norte de El Salvador puede ser una travesía frustrada. La mala condición de los caminos rurales en la zona, o la inexistencia de ellos, es un problema que coinciden en señalar sus líderes y habitantes. La posibilidad de la Carretera Longitudinal del Norte es, por ahora, la principal apuesta de desarrollo que apoyan y ven más cercana" (Portillo, 2006). 
Lo importante es que la construcción de la carretera Longitudinal del Norte no sólo será de tránsito para el comercio, sino que promueva el desarrollo de esta zona marginada, ya que con esta infraestructura sería más fácil llevar programas de energía, de agua potable y otros servicios básicos.
EI PNODT propone un sistema de carreteras especiales que conecten AMSS, Santa Ana, Sonsonate, San Vicente y Zacatecoluca, la nueva carretera Longitudinal del Norte y una serie de carreteras de circunvalación alrededor de las ciudades más importantes, con el objetivo de que las oportunidades de desarrollo existan para todos.

\section{Mapa 3.2}

Sistema vial propuesto por el PNODT

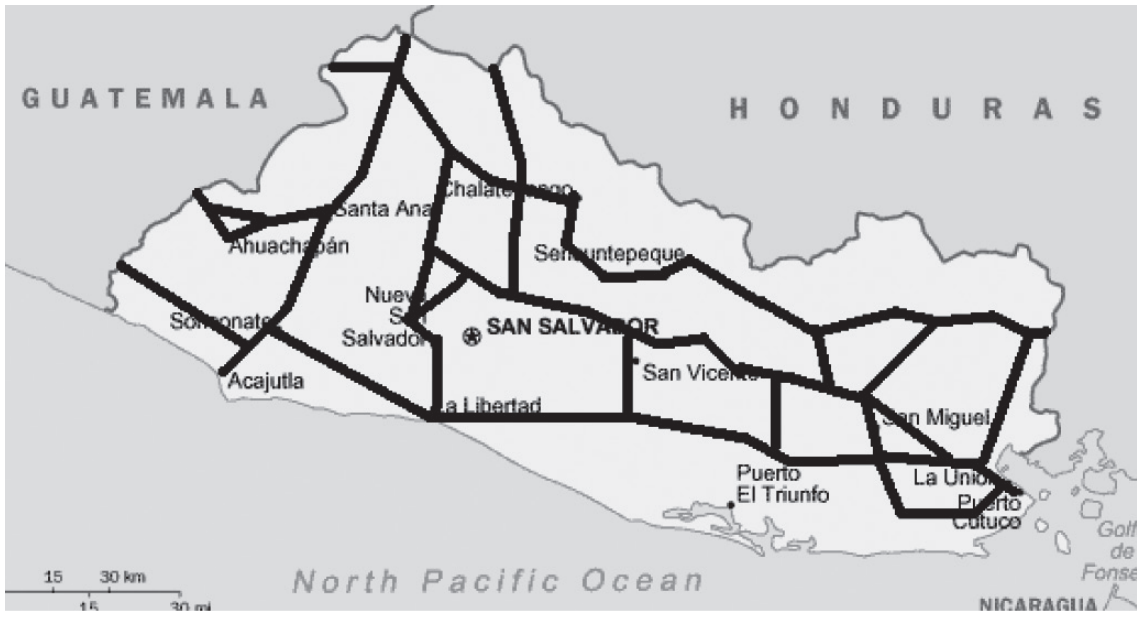

Fuente: PNODT 2004

\subsubsection{Seguridad alimentaria}

A partir de la década de los 90 las políticas implementadas en la economía salvadoreña han tenido un corte neoliberal, lo cual deja vulnerables a las zonas más pobres del país cuya actividad productiva principal es la agricultura. Para hacer frente al deterioro del sector agrícola se propone lo siguiente: a) Minimizar los costos de transacción para el productor.

Por lo general el principal problema que encuentran los productores es a la hora de comercializar su producción. Una alternativa que reduciría sus costos sería la aplicación de la Ley de Competencia que elimine cualquier monopolio o monopsonio que limite las oportu- 
nidades de los productores, al igual que una información acerca del almacenamiento y financiamiento de la producción.

\section{b) Asegurar insumos a los produc- tores}

Con el objetivo de no caer en una situación de crisis alimentaria, lo conveniente es asegurar los insumos a los productores agrícolas como abonos, insecticidas, pesticidas, etc. Esto permite incentivar a los campesinos a reactivar la siembra de granos básicos. c) Mayor productividad a través de tecnología

Esto se refiere a la forma en cómo se produce, los precios tienden a caer cuando una nueva tecnología reduce los costos de su producción. Esto sería una razón por la cual a muchos productores no les es rentable y deciden salirse del mercado. Una alternativa sería apoyar a los productores a que adapten nuevas tecnologías con el fin de aumentar su productividad.

\section{Conclusiones}

Se puede evidenciar la existencia de desequilibrios económicos territoriales en el país. Esto se puede constatar al observar el Censo Económico y Censo de Vivienda 2007 de El Salvador así como también la Matriz Insumo-Producto.

Las causas de los desequilibrios económicos territoriales son varias pero entre las más importantes se encuentran: un proceso histórico que trae consecuencias más notables a partir de la colonización, políticas implementadas por el Estado pero principalmente el funcionamiento en sí de la economía actual, es decir, el modelo económico neoliberal vigente en el país.

Un desequilibrio económico territorial muy grande es el referente a la producción de los diferentes sectores y su distribución espacial, esta producción se concentra en zonas urbanas, principalmente en los departamentos de La Libertad y San Salvador para la zona paracentral, Santa Ana para la zona occidental y San Miguel para la oriental. Muy poca producción se realiza en el resto de departamentos.

La movilidad de la población rural a zonas urbanas y migración al extranjero, ante la falta de generación de ingresos en su localidad, la concentración de la producción industrial en zonas urbanas, desigualdad en acceso a educación, salud y servicios básicos, evidencia los desequilibrios territoriales económicos y sociales.

La poca inversión pública no ha reducido los desequilibrios 
económicos territoriales ya que la mayor parte de la formación bruta de capital fijo proviene del sector privado. Durante los últimos diez años la inversión pública no ha representado más que el $3 \%$ del PIB y su tendencia es a la baja. Al no existir inversión se dificulta el desarrollo de ramas de actividad económicas, lo cual no permite un progreso en el modo de producción de la economía salvadoreña.

El rumbo que tomó El Salvador a finales de los 80 y principios de los 90 jugó un papel importante en la formación y perpetuación de los desequilibrios económicos territoriales. Los programas de ajuste estructural profundizaron estos desbalances, además, el modelo económico seguido por el país y las características que se desprenden de él: desarrollo hacia afuera, tercerización de la economía y la subutilización laboral. Estas consecuencias de la estructura del económico necesitan ser eliminadas para poder corregir los desequilibrios económicos territoriales.

El auge de los sectores de comercio y servicio es notorio, la mayor parte de la actividad económica proviene de las ramas relacionadas a estos dos sectores. Por lo tanto, los territorios que estén relacionados a ellos, generalmente contarán con mayor acceso a oportunidades y servicios. Por otra parte, los sectores como el de la agricultura, que no forma parte importante en el modelo económico actual, se encuentran relegados y marginados. Obviamente, los territorios que subsisten dedicándose a actividades agrícolas obtendrán un nivel de vida inferior que los territorios dedicados a las actividades principales de la economía salvadoreña.

La reactivación de la agricultura debería de ser uno de los principales objetivos de la política pública. Este es un sector esencial que sirve para hacer crecer los demás sectores, pero para el caso de El Salvador, la agricultura se encuentra en completo olvido y con ello todos los agricultores y sus familias que se dedican y viven de dicha actividad en el país.

El Área Metropolitana de San Salvador acapara la mayor parte de los recursos, ejerce una concentración de oportunidades y atrae a personas de otras regiones para establecerse en ella. Esto genera que la población luche por la cantidad de recursos que se encuentran en la misma. Por otra parte, las demás regiones pierden cierto número de personas que podrían ayudarles a alcanzar mayores niveles de desarrollo. Estos territorios se ven beneficiados en la medida que estén relacionados con el AMSS ya que es ahí donde se encuentra el mayor porcentaje de actividad económica.

El país se ve fragmentado en el tema del empleo a nivel de regio- 
nes. La región Norte del Río Lempa tiene la mayor tasa de subempleo del país así como altos índices de pobreza. La nación tiene un aprovechamiento deficiente de las capacidades que tienen las demás regiones. Es por ello necesario hacer un estudio de las ventajas comparativas que presenta cada territorio para especializarse en determinado producto o servicio y volverse más competitivo y eficiente. Así lograrán generar riqueza y a la vez contribuir a mejorar el bienestar de la población.

El tema del gasto público debe verse como una herramienta efectiva para combatir los desequilibrios económicos territoriales. El gasto en educación es muy importante puesto que una población educada tiene mayores probabilidades de encontrar un empleo decente que las que no; además del gasto en salud, para mejorar el nivel de vida de los territorios.

Es necesario tomar en cuenta una perspectiva territorial así como también los factores estructurales que inciden en la economía para formular políticas públicas. Si no se eliminan estos factores estructurales, las políticas públicas no alcanzarán de manera efectiva sus objetivos.
A pesar de que el Estado ha intentado resolver estas diferencias territoriales al querer implementar polos de desarrollo dispersos por el país, no se han tenido buenos resultados y se han creado enclaves que no ayudan al crecimiento de las zonas aledañas. Otra solución ha sido la de crear infraestructura de conectividad en las zonas empobrecidas, sin embargo, la solución vendrá de conectar o relacionar estos territorios con los territorios generadores de riqueza en el país.

La inclusión de las perspectivas de otras ciencias ayuda a comprender de una mejor manera las causas y posibles soluciones a los desequilibrios económicos territoriales. Un estudio interdisciplinario podría brindar respuestas e insumos más completos para aminorar los desequilibrios económicos territoriales.

Para finalizar, es necesario recalcar la importancia de hacer de los desequilibrios económicos territoriales un tema de la agenda política para propiciar las discusiones de diferentes esferas de la sociedad y obtener así una solución interdisciplinaria al problema sin olvidar que los desequilibrios económicos territoriales no se corregirán hasta que sean solventados los factores estructurales que los provocan. 